\title{
ELECTRICITY CONSUMPTION ANALYSIS AND MANAGEMENT FOR DIFFERENT RESIDENTIAL BUILDINGS IN JEDDAH, SAUDI ARABIA
}

\author{
AFAF D. ALMOALLEM \\ Department of Industrial Engineering, University of Business and Technology, Saudi Arabia.
}

\begin{abstract}
The electricity consumption of different domestic dwellings during the year in Saudi Arabia has been studied and analyzed. Jeddah is considered to be the second largest city in Saudi Arabia, where the weather is harsh most of the year. The average temperature for the warmest months is $36.34{ }^{\circ} \mathrm{C}$, while it is $29.25{ }^{\circ} \mathrm{C}$ in the remaining months. This is relatively high compared to the other cities in Saudi Arabia. The aim of this research was to conduct a survey to evaluate Jeddah residents' electricity consumption for domestic dwellings in terms of type, size, and age of the dwellings. The survey also includes the number of residents in each dwelling, their type, and the total number of air-conditioning (AC) systems. Other appliances used in a dwelling are also included in the questionnaire as well as details of the thermal insulation in walls and the window glazing systems used. Analyzing the results shows that the ratio of electricity consumption due to the AC systems to the total consumption during the summer is $46.13 \%$. However, this ratio falls to $17.15 \%$ in winter. This illustrates the huge impact of AC systems on total consumption. The results suggest that using window glazing systems will reduce consumption by $11 \%$, while using thermal insulation will reduce the consumption by $14 \%$. Consequently, the use of these two technologies is highly recommended in terms of reducing electricity consumption. Finally, a matrix plot and a probability plot are provided as illustrations in this work.

Keywords: air-conditioning systems, domestic dwelling, electricity consumption, Jeddah, thermal insulation, window glazing systems.
\end{abstract}

\section{INTRODUCTION}

The Kingdom of Saudi Arabia (KSA) is recognized for its extensive reliance on fossil fuel energy and the well-established electricity regulatory framework for its built environment [1]. The risk of losing this independence with regard to full usage has led to a revision by consumers of these energy resources resulting in recommending a strategy that could reduce and adjust the usage. In 2015, the consumption of electricity in different sectors was calculated to be around $49 \%$ by domestic residents relative to the total use of electricity per year, while industry used around 19\%. This was followed by $16 \%$ for commercial use, $11 \%$ for government use, and only $2 \%$ for agricultural use [2].

A study in the KSA showed that the residential buildings accounted for $50 \%$ of the electricity consumption [3]. This was confirmed by several works from the King Abdullah Petroleum Studies and Research Center (KAPSARC) $[4,5]$. About 5\%-8\% is the yearly average growth in total electricity consumption, which indicates that oil production and oil consumption would be equal in 2035 [6]. The consumption of electricity in residential buildings, as indicated by many papers, has been compared in different regions throughout the world [7]. The following is an illustration of some of these papers' findings. 
The average electricity demand of 10 assigned houses in Finland with differences in building structure was calculated by Holopainen et al. [6]. They calculated that the electricity consumption of five buildings categorized as recent-build low-electricity houses was 120 $\mathrm{kWh} / \mathrm{m}^{2}$, while the average was $323 \mathrm{kWh} / \mathrm{m}^{2}$ for the other five buildings categorized as conventional houses. This variation in electricity consumption was on average 2.7 times lower in the first category compared to that of the second category. The study also indicated that the room temperature was high and varied in both categories. However, the occupants experienced more variability in terms of electricity demand due to the differences between the rooms' temperature in the same building [6].

Alrashed and Asif presented a survey claiming that $52 \%$ of the consumed electricity in Dhahran, KSA is due to residential buildings irrespective of the type of building [2]. The conclusion was that the saving in electricity consumption was due to using mini-split air conditioning (AC), AC systems, thermal insulation, and window glazing systems. There appeared to be $30 \%$ less electricity consumption in buildings with than those without these specifications.

The annual average electricity consumption was found to be $92.6 \mathrm{kWh} / \mathrm{m}^{2}$ in Qassim region, KSA [8]. According to this work, the average electricity consumption did not vary much between different types of dwellings (villas or apartments) and had the same average value. In addition, $66.5 \%$ of the annual consumption is due to the use of $\mathrm{AC}$ and $14.7 \%$ was for domestic appliances. In order to decrease this high consumption of electricity, the study suggested the installation of a standard envelope in buildings to reduce the AC load by $43 \%$. Moreover, if the residents adjusted the AC temperature setting point to $24{ }^{\circ} \mathrm{C}$ instead of $22{ }^{\circ} \mathrm{C}$, there would be a drop of $11.1 \%$ in terms of average electricity consumption.

The results of the residential building stock model in the KSA indicate that implementing an effective retrofit program based on factors such as housing type, vintage, and location could significantly reduce annual electricity consumption by up to $50 \%$, while decreasing carbon emissions and reducing electricity generation capacities [9]. The results of another study clearly indicate that in order to minimize energy consumption, it is imperative that different building types be constructed based on the weather and geographical location [10].

As shown in the previous related works, electricity consumption in Jeddah, KSA has not been studied in detail. Consequently, the main source of electricity consumption and the way in which electricity should be managed for different residential buildings need intensive study. Jeddah city has a unique climate, different from that of other cities in KSA, as it has a higher temperature in winter than that of the other main cities in Saudi Arabia [9, 12].

The structure of this paper is as follows: in the next section, the main weather characteristics of Jeddah city, KSA, during the year will be considered. Section 2 will give details of the analysis based on an electricity consumption model and the calculation equations used in this study with regard to total electricity consumption. The data collection technique and the methodology used in this work are explained in Section 3. Finally, the main results and an overall discussion of each aspect of the data will be given in Section 4 prior to the main conclusion in the Section 5.

\subsection{Jeddah weather characteristics}

Jeddah is the largest city in the western region of Saudi Arabia. The weather in this city is humid most days, and the temperature is high most of the year [6]. This basically leads to a high level of electricity consumption during most of the year. Jeddah is located in the middle of the east coast of Saudi Arabia and is considered the economic and tourism capital of the 
country. Its population is estimated to be around 3.5 million, and it is the second largest city after Riyadh [11].

Jeddah is the main destination for both sea and air pilgrims, as well as those traveling by road. The city has grown during the last two decades of the 20th century; this has increased electricity consumption in order to find economical ways of dealing with the coastal humidity. When comparing the average temperature of the three biggest cities in the KSA using the Atlas website, the observations in both Riyadh and Dharan were very similar, although slightly different during winter in Jeddah, as shown in Table 1 [12]. In addition, the total average cooling degree days (CDD) from 2005 to 2014 is calculated using Hitchin's method for a base temperature of $26^{\circ} \mathrm{C}$ with details given in Table 1 [13]. As can be seen, Jeddah has the highest CDD value. This means that Jeddah needs more annual cooling energy than Riyadh and Dharan.

The month in Jeddah with the highest average high temperature is July at $39.4{ }^{\circ} \mathrm{C}$, while the month with the lowest average high temperature is January at $29^{\circ} \mathrm{C}$. The warmest month in Riyadh, with the highest average temperature, is August at $43.6^{\circ} \mathrm{C}$, while the month with the lowest average temperature is January at $20.2{ }^{\circ} \mathrm{C}$. However, the warmest month in Dhahran, is July, with an average temperature of $43.3{ }^{\circ} \mathrm{C}$, while the month with the lowest average temperature is January at $20.8{ }^{\circ} \mathrm{C}$. The yearly weather in Jeddah has been categorized in this study as 7 months of hot climate, from April to September, and 5 months of acceptable climate, from October to March. The division of the months into hot and acceptable depends on the observed temperature. This has been considered in this paper based on the data obtained from Atlas weather in Jeddah, Saudi Arabia. The data obtained are as illustrated in Fig. 1 [12].

\section{ELECTRICITY CONSUMPTION MODEL}

The rate at which electricity is transferred from one point to another is known as the power [14]. Electricity consumption can be calculated using the equation

$$
E_{c}=P \times T
$$

where

- $\left(E_{c}\right)$ is the electricity consumption,

- $(P)$ is the power in watts, and

- $(T)$ is the total working hours.

As an example, the total electricity consumed by a single device of 1000 watts operated for $2 \mathrm{~h}$ is $1000 \mathrm{~W} \times 2 \mathrm{~h}=2 \mathrm{kWh}$. Hence, the total electricity consumption, $E_{t}$, for different appliances can be calculated using the equation

Table 1: Average high and low temperature and CDD in Jeddah, Riyadh, and Dharan.

\begin{tabular}{llllll}
\hline & \multicolumn{4}{l}{$\begin{array}{l}\text { Average high } \\
\text { temperature }\left({ }^{\circ} \mathbf{C}\right)\end{array}$} & \multicolumn{2}{l}{$\begin{array}{l}\text { Average low } \\
\text { temperature }\left({ }^{\circ} \mathbf{C}\right)\end{array}$} & Average CDD \\
Location & Summer & Winter & Summer & Winter & Base temperature 26 ${ }^{\circ} \mathbf{C}$ \\
\hline Jeddah & 36.34 & 29.25 & 24.32 & 20.20 & 1463 \\
Riyadh & 36.46 & 21.80 & 22.89 & 10.10 & 1593 \\
Dharan & 39.20 & 23.80 & 25.29 & 10.85 & 1485 \\
\hline
\end{tabular}




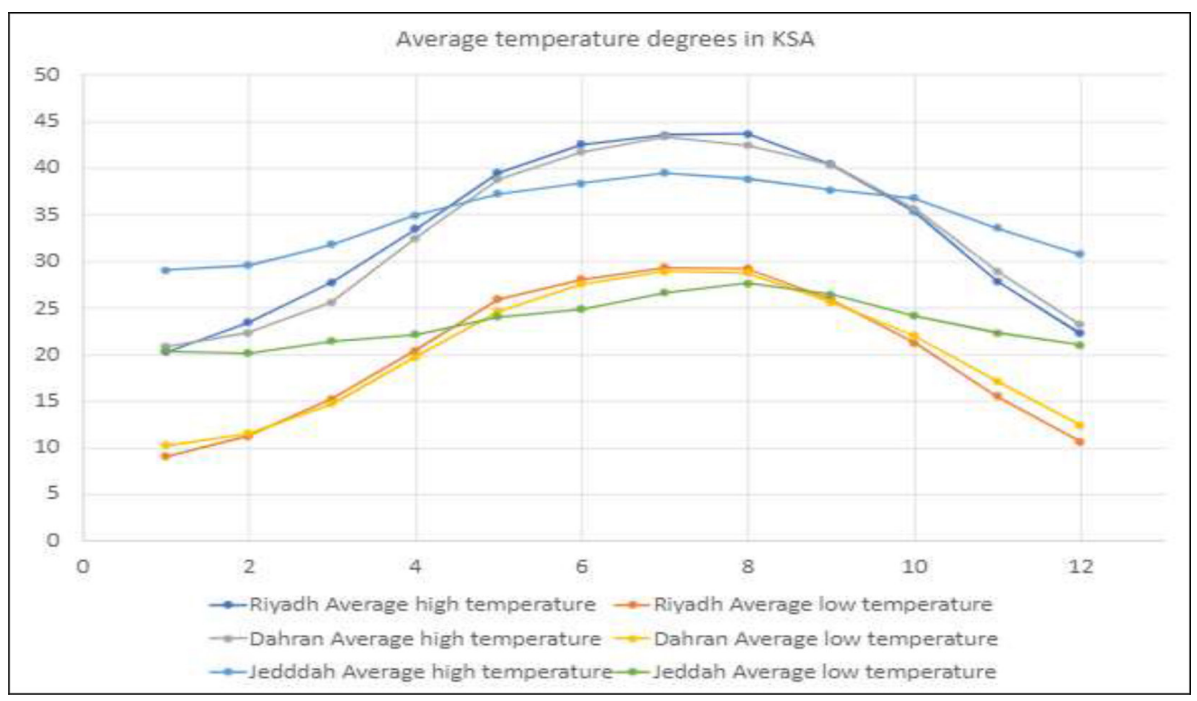

Figure 1: A comparison of the yearly average low and high temperatures between Dhahran, Riyadh, and Jeddah cities, KSA.

$$
E_{t}=\Sigma P(\text { each app. }) \times T \text { (each app.) } \mathrm{kWh}
$$

In this work, the total number of appliances in each apartment/villa and the estimated working hours for each one will be considered as shown in Table 2 [2].

Table 3 illustrates the consumption tariffs for all categories of electricity consumption, as given by Saudi Electricity Company [15].

This is in addition to 10 Saudi Riyals (SR) for meter services and a $15 \%$ VAT charge. The total amount required for electricity consumption in kilowatt-hour in SR can be calculated using the following assumptions:

a) Consumption is less than $6000 \mathrm{kWh}$ :

$$
\text { Total bill }=\left(E_{t} \times 0.18\right)+\left(E_{t} \times 0.18\right) \times 15 \%+10 \mathrm{SR}
$$

b) Consumption is more than $6000 \mathrm{kWh}$ :

Table 2: Electricity consumption based on the appliance.

\begin{tabular}{lll}
\hline Appliance & Electricity consumption & Unit \\
\hline Fridge freezer & $0.8-1.6$ & {$[\mathrm{kWh} / \mathrm{day}]$} \\
Freezer & $0.5-1.5$ & {$[\mathrm{kWh} /$ day $]$} \\
Electric kitchen stove & $1-2$ & {$[\mathrm{kWh} / \mathrm{day}]$} \\
Microwave & $0.12-0.2$ & {$[\mathrm{kWh} / 10 \mathrm{~min}]$} \\
Drying cabinet & $3.5-4.7$ & {$[\mathrm{kWh} / 5-7 \mathrm{~kg}]$} \\
Refrigerator & 225 & {$[\mathrm{kWh} / \mathrm{h}]$} \\
Tumble dryer & $3.2-4.6$ & {$[\mathrm{kWh} / 5-7 \mathrm{~kg}]$} \\
\hline
\end{tabular}


Table 3: Residential consumption tariffs

\begin{tabular}{ll}
\hline Consumption categories $[\mathbf{k W h}]$ & Residential [Halalah/kWh] \\
\hline Consumption $<6000$ & 18 \\
Consumption $>6000$ & $18(<6000)$ \\
& $30(>6000)$ \\
\hline
\end{tabular}

$$
\text { Total bill }=[(6000 \times 0.18)+((E t-6000) \times 0.30)] \times 1.15+10 \mathrm{SR}
$$

Equations (3) and (4) are used to calculate the total amount (SR) based on the electricity consumption. Hence and by knowing the total bill amount, the usage percentage of any appliance can be calculated using the equation

$$
\text { Appliance usage percentage }(\mathrm{R})=\frac{E_{t}(\text { for any appliances })}{E_{t}(\text { for all appliances })}
$$

\section{DATA COLLECTION PROCESS}

The focus in this paper is only on the domestic sector in terms of residential buildings categorized into apartments, houses, and villas, in order to make recommendations with regard to reductions in electricity consumption. To investigate the electricity consumption peaks in residential buildings, a survey has been designed to study various districts in Jeddah. This includes the main factors that increase the utilization of electricity and are the basis of the electricity bills. Using a questionnaire survey, randomly selected dwellings were investigated by asking residents 25 questions using drop-down lists, multiple choice questions, and filling the blank sections. The questions sought data for the average electricity bills for summer as well as the electricity consumption during winter. The survey also included difference characteristics: the type of dwelling, the dwelling size in square meters, and the dwelling age. In addition, data were obtained with regard to the number of residents, the type and number of AC systems, and other factors that can affect electricity utilization such as the appliances used in the house, thermal insulation installations for walls, and window glazing systems. A total of 128 responses were analyzed. The survey data were gathered though an online approach using various applications including WhatsApp and Email and offering help for any enquiries with regard to the questionnaire.

The weather in Jeddah is hot and humid, which increases the usage of AC systems regardless of the type or size of building. Due to the lack of data about the types of thermal insulation materials used in the various building, all types of thermal insulations were assumed to be similar.

In order to calculate the percentage of use of each appliance, the total electricity consumption was calculated using Eqns (3) or (4) depending on the range showed on the bill. Then, by using eqn (1), the electricity consumption for each device in kilowatt-hour, can be calculated. Hence, the percentage electricity consumption of any appliance with respect to overall consumption can be given using eqn (5).

\section{RESULTS AND DISCUSSION}

Electricity consumption in Jeddah city, KSA has been studied during both summer and winter by analyzing the data obtained from a well-designed survey. Statistical data for 128 responses 
are used to obtain the probability plot and matrix plot using the Minitab software package [14]. The 128 responses to the 25 questions are then scrutinized, and the results obtained are summarized in the following sections.

The energy consumption of AC systems is calculated using the feedback from the survey. There are some questions in the survey with regard to the total number of ACs, their type in terms of energy consumption, and the average working hours in summer and winter. This information can be easily used to calculate the energy consumed by the ACs during summer and winter. Similarly, the average electricity bill in winter and summer for each user is obtained from the distributed survey. It should be noted that the AC efficiency and air tightness of the buildings are not taken into consideration in the calculation of the total energy consumption using eqns (3) and (4).

\subsection{Statistical data analysis}

The Minitab software package was used to run 128 data results. The results of the analysis of the effect of various characteristics with regard to each question are shown in the figures. Figure 2a represents the plot of the normal probability distribution of the ratio of energy consumption by AC systems to the total energy consumption during the summer, where the approximate data fit shows normal behavior with a $p$-value less than 0.005 . This indicates that there is a statistically significant association between the AC electricity consumption in summer and the increase in the percentages of electricity usage. According to Fig. 2a, most data density lies around the mean of 0.4613 and the standard deviation is 0.06346 . In Fig. $2 \mathrm{~b}$, the plot of normal probability distribution of the ratio of energy consumption by AC systems to the total energy consumption in winter with the same $p$-value shows that the mean is 0.1775 and the standard deviation is 0.03568 . The decrease in the mean of AC electricity consumption in Fig. 2b shows less variation in the results due to the lower usage of AC systems during the winter.

Figure 3a depicts the matrix plot, which shows the relationship between the ratio of energy consumption by AC systems to the total energy consumption in summer versus the customer numbers. This indicates a high variation in the consumption of the AC systems with an average of $46 \%$. On the other hand, Fig. 3b shows a lower average of $17.75 \%$, with the variation being limited to between $10 \%$ and $25 \%$, with a couple of values above this range.

\subsection{User response data analysis}

The typical average working hours for all used and considered appliances are illustrated in Table $4[17,18]$. However, the average working hours per day is taken from the responses to the distributed survey.

The electricity consumption has, among many other factors, been illustrated using the responses to the survey. By analyzing the obtained data, one can observe that the ratio of electricity consumption by ACs has been calculated using eqn (5) and found to be $46.13 \%$ during summer and $17.15 \%$ during winter. The difference between the ratio of electricity consumption by $\mathrm{AC}$ between summer and winter is equal to the electricity consumption of the $\mathrm{AC}$ in summer subtracted from the electricity consumption of the $\mathrm{AC}$ in winter, divided by the obtained results for the total electricity consumption of AC in summer. The red line in Fig. 4 illustrates the ratio of the total electricity consumption by AC in winter, the blue line shows the ratio in summer, while the yellow line shows the ratio of the difference in electricity con- 


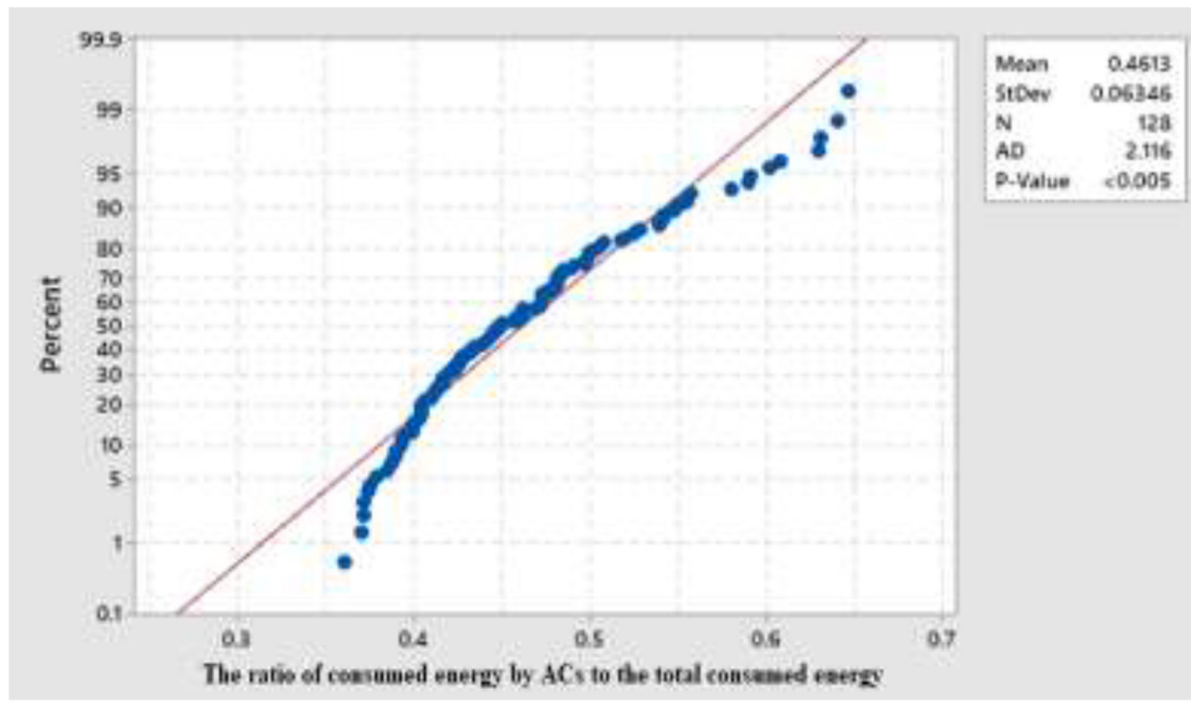

(a)

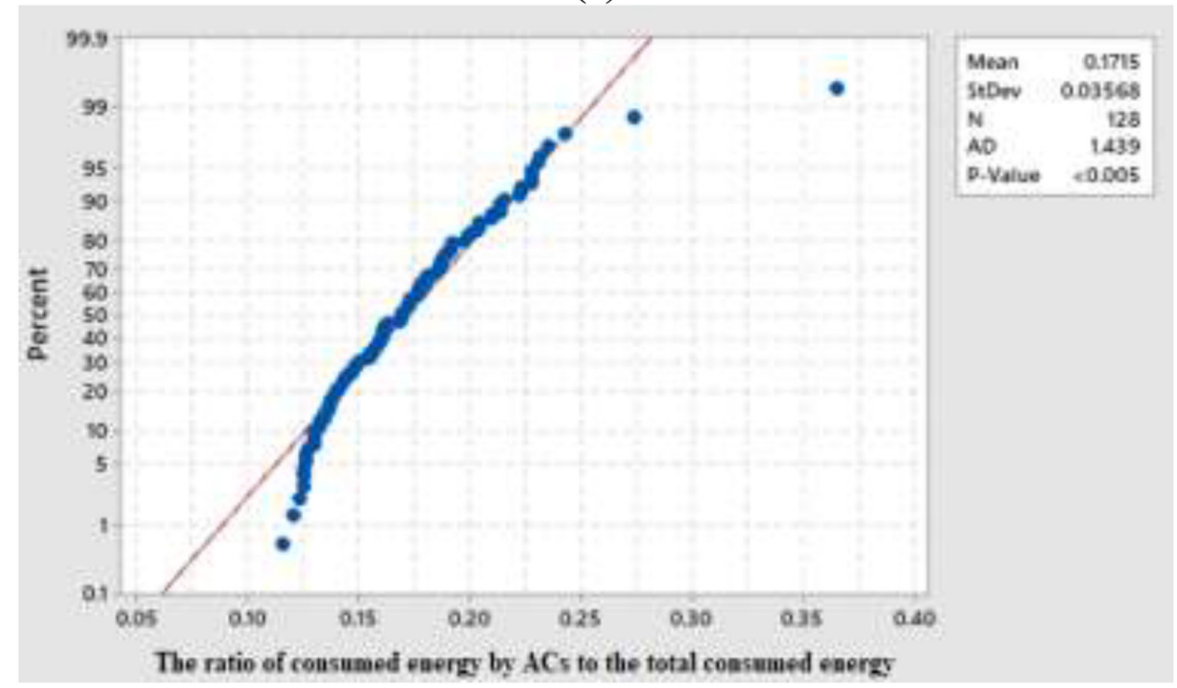

(b)

Figure 2: Probability plot of the ratio of energy consumption by AC systems to the total energy consumption in (a) summer and (b) winter.

sumption by $\mathrm{AC}$ in summer and winter. The results show that the ratio in winter is lower than that in summer for the same consumer at all points, red line versus blue line. However, the difference between the two seasons emphasizes, as shown by the yellow line, the variation in consumer AC usage in some cases.

The survey results indicate, as shown in Fig. 5a, that $37 \%$ of the dwellings are more than 15 years old. This is followed by $25 \%$ of the dwellings, which are between 5 and 10 years old. Also, $20 \%$ of the buildings are less than 5 years old, whereas 10-15 years of age dwellings make up only $18 \%$ of the total of 128 dwellings. Figure $5 \mathrm{~b}$ shows that the electricity con- 


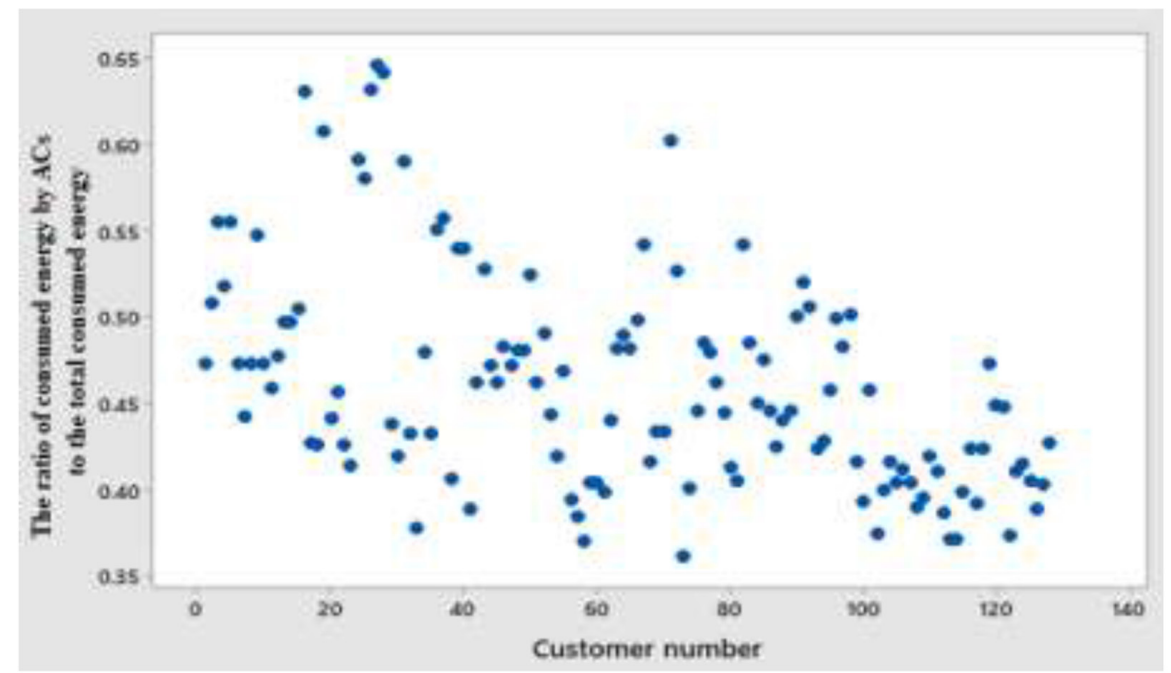

(a)

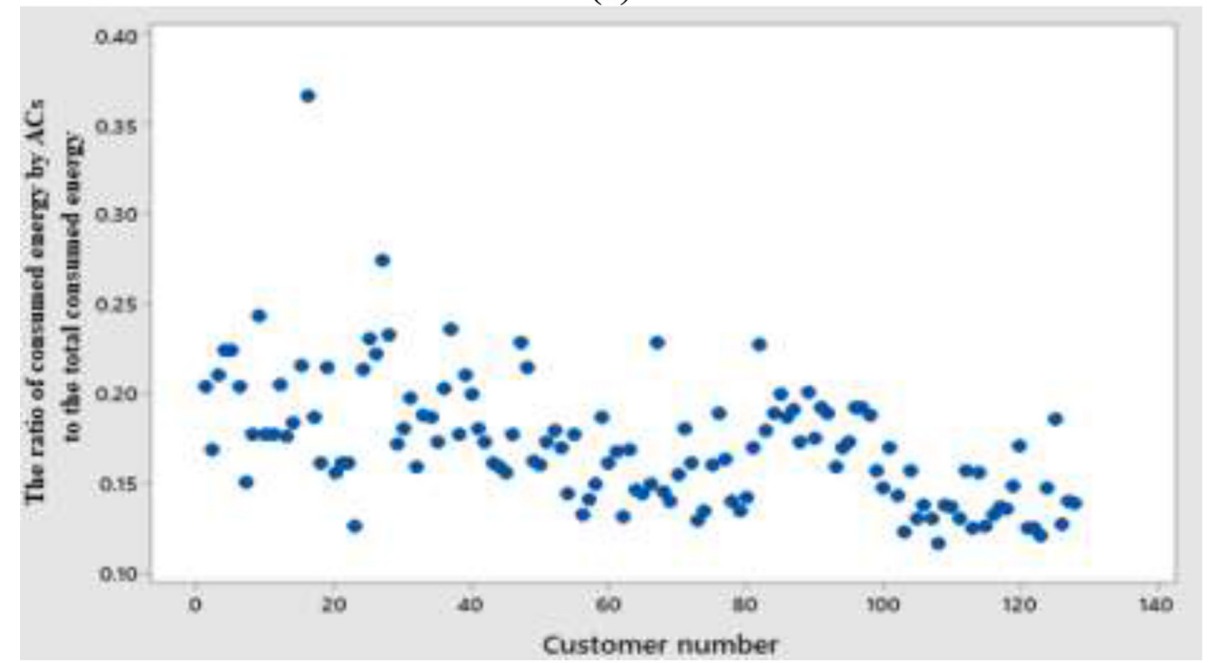

(b)

Figure 3: Matrix plot of the ratio of energy consumption by $\mathrm{AC}$ systems to the total energy consumption in (a) summer and (b) winter.

sumption differs in summer (the blue columns) than in winter (the red columns). Electricity consumption during summer is higher in all dwellings regardless of the age of the building, while all electricity performance during the winter is low and the highest value intake is 616 $\mathrm{kW} / \mathrm{h}$ for old buildings. This observation shows various values associated with the age of the dwelling, in that the value increases in old dwellings (15-year-old dwellings) in both summer (with an average of $2957 \mathrm{~kW} / \mathrm{h}$ ) and winter (with an average of $616 \mathrm{~kW} / \mathrm{h}$ ).

As clearly noted in Fig. 5b, the average energy consumption in winter and summer for buildings aged between 5 and 10 years is less than the energy consumed by the building with less than 5 years of age. The reason for these unexpected values can be explained when using the survey feedback, as there is a question related to thermal insulation for each building 
Table 4: Working hours for the used appliance [17, 18].

\begin{tabular}{lll}
\hline & \multicolumn{2}{c}{ Average working hours per day } \\
Appliance & Winter & Summer \\
\hline Air conditioner & 4 & 22 \\
Refrigerator & 24 & 24 \\
Washing machine & 0.3 & 0.3 \\
Lighting & 12 & 12 \\
Electrical oven & 2 & 2 \\
Dryer & 0.3 & 0.3 \\
\hline
\end{tabular}

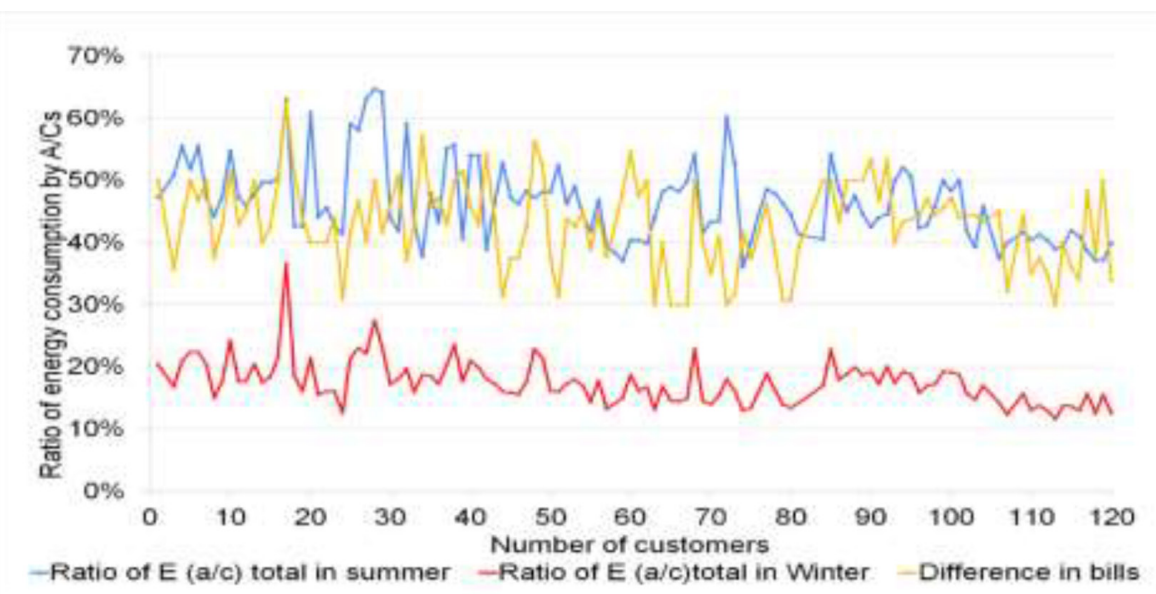

Figure 4: Ratio of electricity consumption by $\mathrm{AC}$ in winter and summer, and the difference between winter and summer.

and one relating to the age of the building. Hence, it was found that almost $50 \%$ of the new buildings (less than 5 years of age) do not have thermal insulation. On the other hand, $65 \%$ of the buildings aged between 5 and 10 years have thermal insulation, which gives an important indication of the role of using thermal insulation in saving energy.

As shown in Fig. 6a, the types of dwellings studied in the survey are apartments, houses, and villas. The results from 128 participants show that $51 \%$ of the dwellings are apartments, $27 \%$ are villas, and $22 \%$ are houses. Figure $6 \mathrm{~b}$ dealing with the consumption of electricity in these types of dwellings shows that the highest consumption is in villas during the summer $(3303 \mathrm{~kW} / \mathrm{h})$ and in winter $(688 \mathrm{~kW} / \mathrm{h})$. Apartments come second in summer $(2495 \mathrm{~kW} / \mathrm{h})$ and in winter $(520 \mathrm{~kW} / \mathrm{h})$. Finally, the houses come last in summer $(2374 \mathrm{~kW} / \mathrm{h})$ and in winter $(495 \mathrm{~kW} / \mathrm{h})$. We cannot ignore the significant difference in electricity consumption between winter and summer in all type of dwellings. In addition, and to clarify the energy consumption for each building type with respect to the area in square meters, the average area for each building type has been added to Fig. $6 \mathrm{~b}$. Hence, the energy consumption per square meters for each building type is illustrated in Table 5 . 


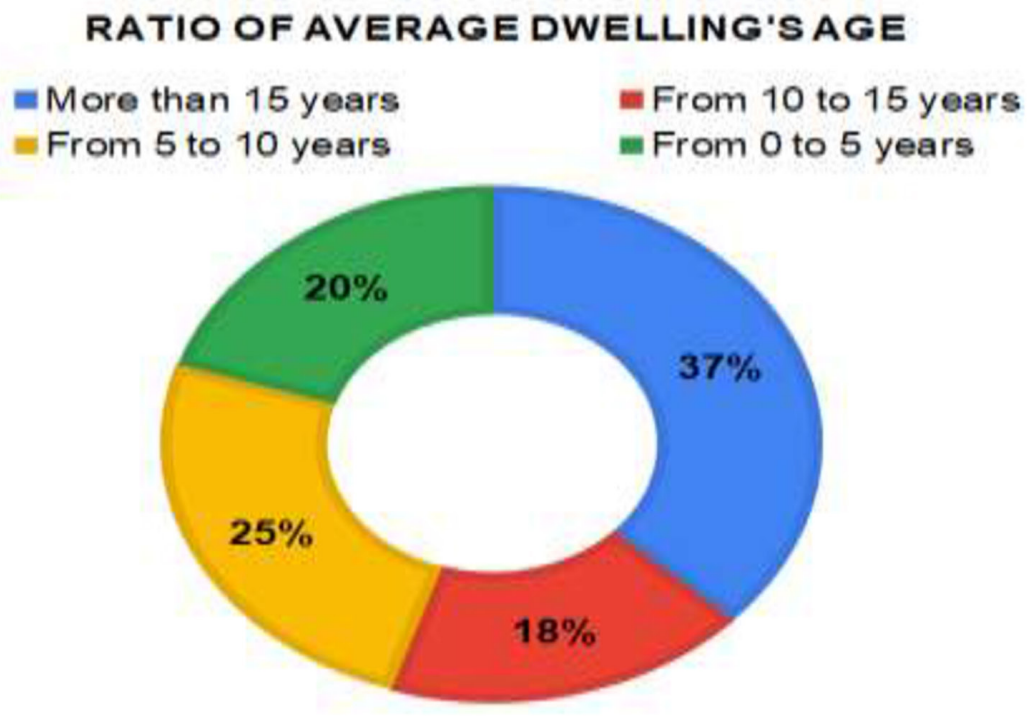

(a)

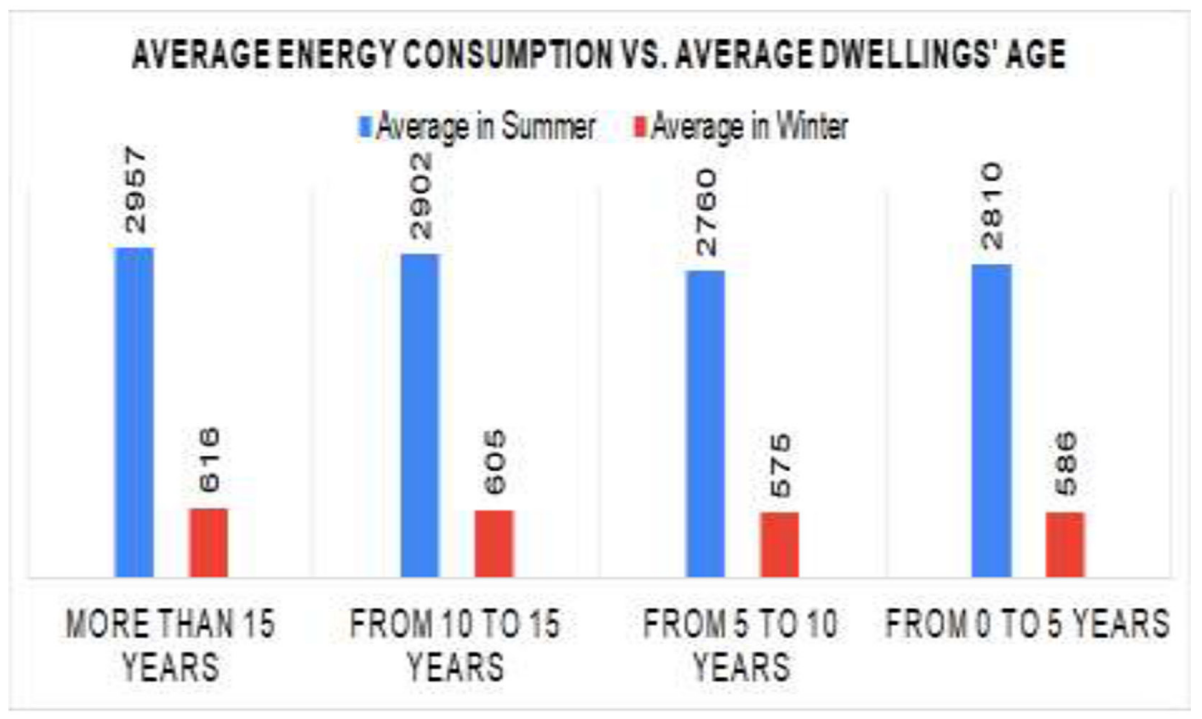

(b)

Figure 5: (a) Average dwellings' age (percentage); (b) average electricity consumption for dwellings of different ages.

The use of electricity and gas is common in KSA for cooking using stoves with ovens. As can be seen in Fig. 7a, the survey results show a ratio of $42 \%$ counting for electrical and $41 \%$ counting for gas-fuel. It is cheaper to use gas and it leads to $4 \%$ savings in electricity 


\section{RATIO FOR TYPES OF DWELLINGS}

=Duplex =Apartment =Villa

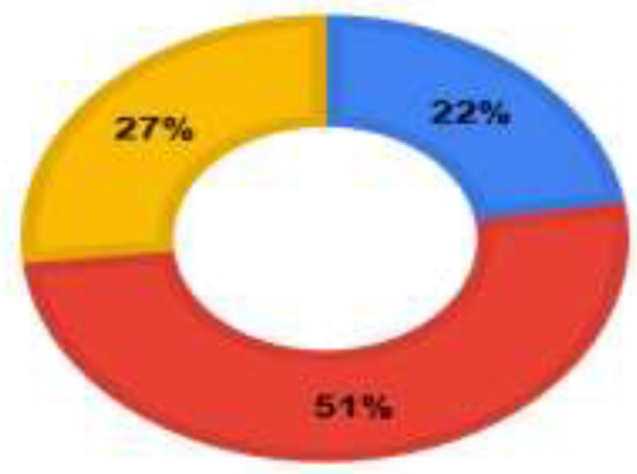

(a)

\section{AVERAGE ENERGY CONSUMPTIONIN DIFFERENT TYPE OF DWELLINGS}

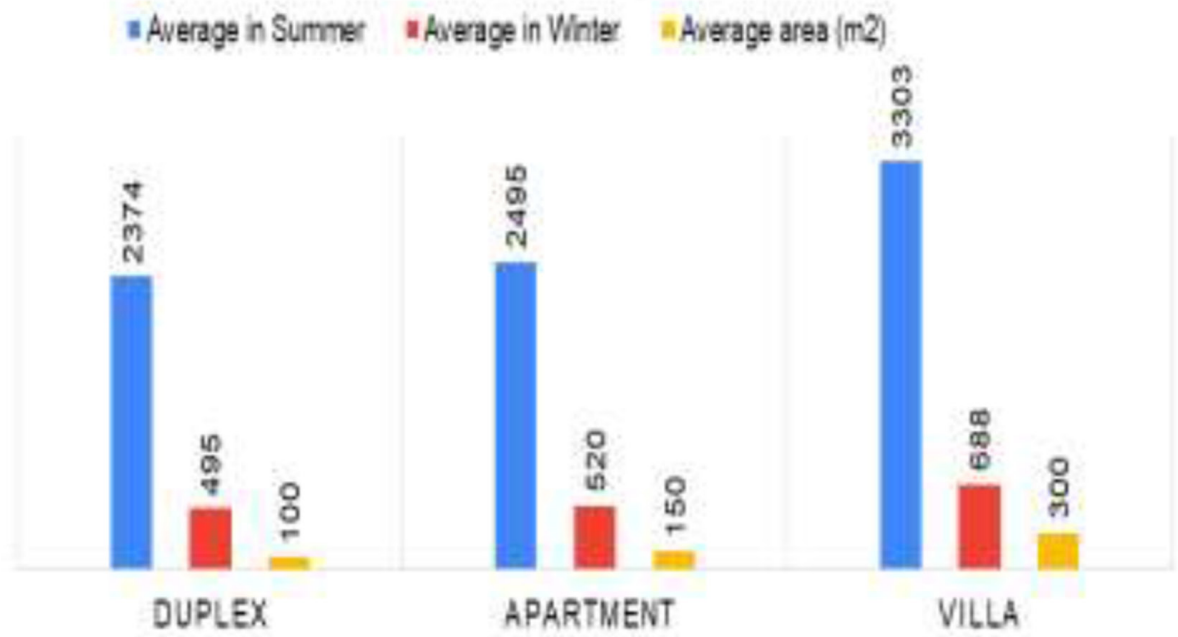

(b)

Figure 6: (a) Ratio of types of dwellings; (b) average consumption in different types of dwellings in summer and winter.

consumption during summer, while there is a decrease in consumption by $1.3 \%$ during winter as clearly shown in Fig. 7b.

The survey results shown in Fig. 8a reveal that about $41 \%$ of the surveyed dwellings have 5 or fewer AC systems, $38 \%$ have from 6 to $10 \mathrm{AC}$ systems, and $21 \%$ have more than $10 \mathrm{AC}$ 
Table 5: Energy consumption per square meters for different building types.

\begin{tabular}{ll}
\hline Building type & Energy consumption per $\mathbf{k W h} / \mathbf{m}^{\mathbf{2}}$ \\
\hline Duplex & 23.74 \\
Apartment & 16.63 \\
Villa & $\mathbf{1 1 . 0 1}$ \\
\hline
\end{tabular}

systems. The $41 \%$ corresponds to a low level of electricity consumption when compared to the second or third category as shown in Fig. 8b. The lowest consumption is in winter with $575 \mathrm{~kW} / \mathrm{h}$, while the highest is obtained when using more than $10 \mathrm{AC}$ system during summer with $3144 \mathrm{~kW} / \mathrm{h}$.

The highest proportion of residents live in apartments, as clearly illustrated in Fig. 9a, which indicates an increase in electricity consumption with more residents at the same dwelling as shown in Fig. 9b. It was found that $5000 \mathrm{kWh}$ are consumed in summer with more than 10 residents in a house. This average is still high in winter with $1042 \mathrm{kWh}$ compared to apartments with few residents.

The window glazing systems detailed in Fig. 10a were found to be used in $43 \%$ of the surveyed dwellings. The survey results show that while the use of window glazing systems has increased, leading to electricity savings of $11.16 \%$ during summer, it also increases the saving during winter by almost the same amount (11.14\%), which shows the importance of this system in each window in hot cities like Jeddah as can be seen in Fig. 10b. Characteristics of the glazing system used, such as the solar heat gain coefficient and the thickness of the glass, are not considered in these calculations.

The survey results in Fig. 11a indicate that the use of thermal insulation is almost similar to non-insulation, with a $1 \%$ difference. With $39 \%$ of the surveyed dwellings using thermal insulation, the lowest electricity consumption among the other dwelling is $526 \mathrm{~kW} / \mathrm{h}$ in winter and $2527 \mathrm{~kW} / \mathrm{h}$ in summer as shown in Fig. $11 \mathrm{~b}$. There is a $14.6 \%$ increase in savings with regard to electricity as a result of thermal insulation during the winter.

\section{CONCLUSION}

The analysis of electricity consumption in Jeddah during the year is dealt with in this work. The 128 responses to the survey with regard to different dwelling types show that $51 \%$ of the participants are living in apartments. Moreover, the average electricity consumption is high in villas compared to apartments. The shared wall in a duplex makes the consumption of electricity the lowest among the three types of dwelling, although the age of the building increases electricity consumption by $4 \%$ for every 10 years of age. The survey results also showed the oven-type effect on the electricity consumption as well, where there are $41 \%$ gas-fuel-ovens and $42 \%$ of electrical-fuel-ovens; $1 \%$ more electricity consumption by the electrical-fuel-ovens than by gas-fuel-ovens. Based on this, gas ovens are to be preferred in order to increase electricity saving or '...reduce electricity consumption...'. The ratio of electricity consumption by ACs to total consumption is $46.13 \%$ in summer and $17.15 \%$ in winter. Moreover, using window glazing systems will reduce electricity consumption by $11 \%$, while there will be a $14 \%$ reduction in electricity consumption when using thermal insulation systems. In conclusion, greater use of gas ovens, window glazing systems, and thermal insulation systems are highly recommended as a means of reducing electricity consumption. 


\section{RATIO OF DIFFERENT OVENS' FUEL IN DWELLINGS}

= Gas =Electricity $=$ Both

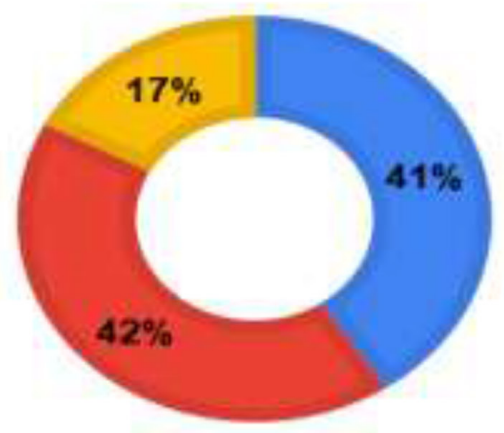

(a)

\section{AVERAGE ENERGY CONSUMPTION IN DWELLINGS VS. TYPES OF OVENS' FUEL USED IN SUMMER OR WINTER}

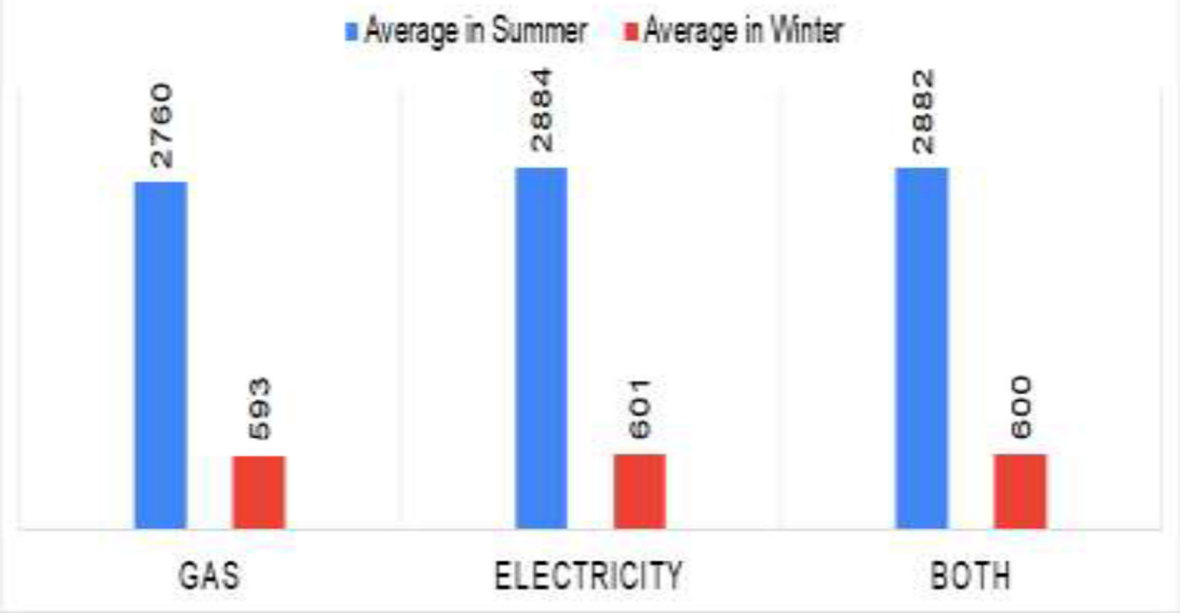

(b)

Figure 7: (a) Ratio of types of oven-stove fuel; (b) average electricity consumption versus types of fuel for oven-stoves.

\section{ACKNOWLEDGMENTS}

I would like to thank Dr Ali Elrashidi for the support and assistance that I have received throughout the process of completing my paper. It was an honor for me to be working with him. His experience was invaluable in formulating the survey questions and methodology. His insightful feedback helped me analyze the results and sharpen my thinking and brought my work to a higher level. 


\section{RATIO OF DIFFERENT TYPES OF A/C IN DWELLINGS}

=5 or less $=$ From 6 to $10=$ More than 10

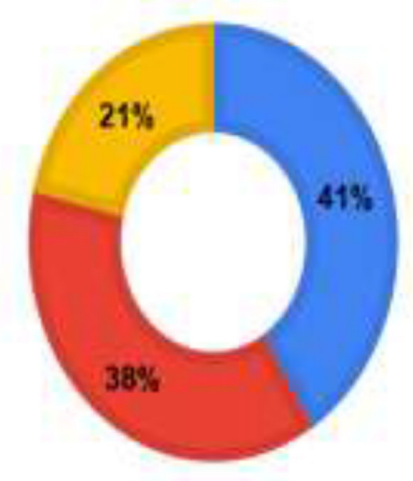

(a)

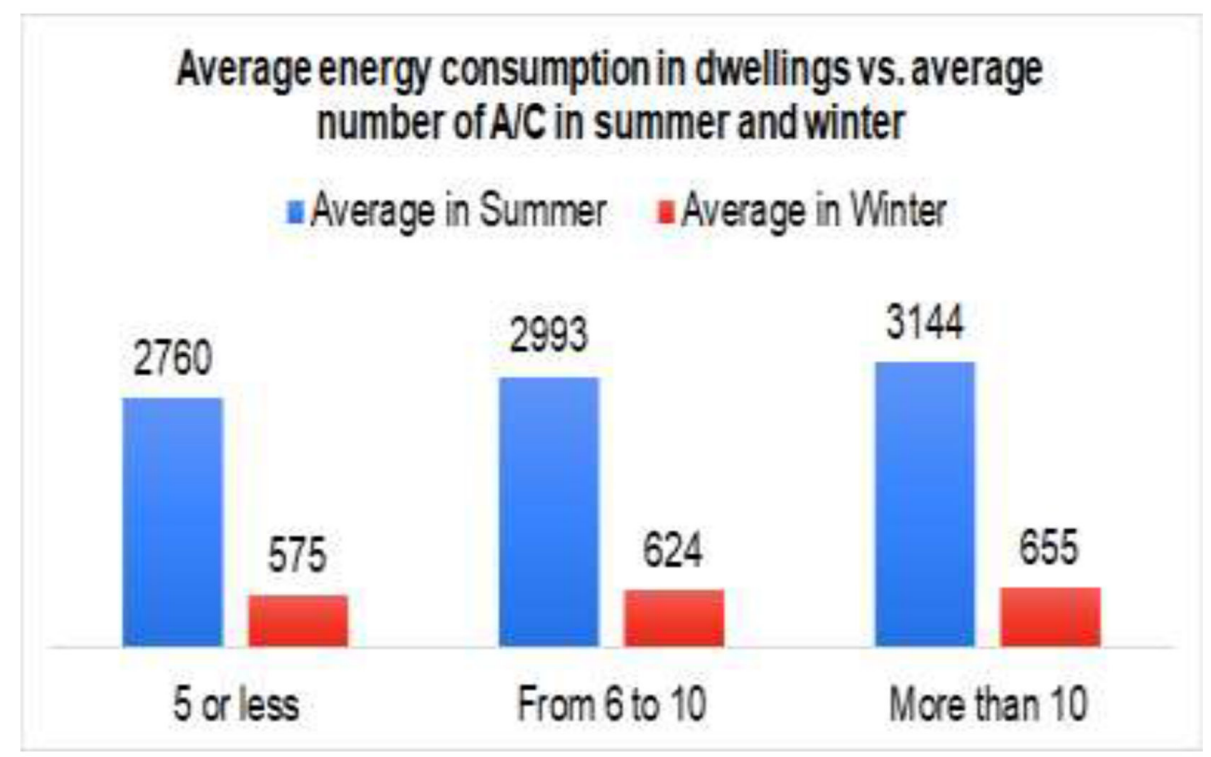

(b)

Figure 8: (a) Ratio of number of ACs in the dwelling; (b) average electricity consumption versus average number of ACs in summer and winter. 


\section{RATIO OF AVERAGE NUMBER OF THE RESIDENTS}

is or less $=$ From 6 to $10=$ More than 10

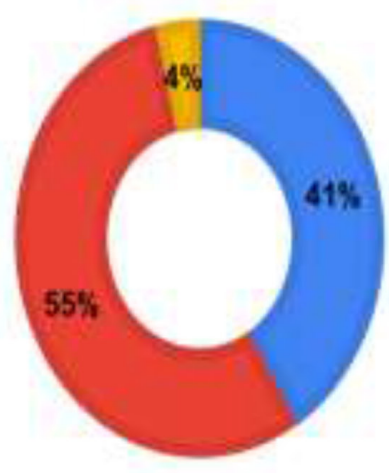

(a)

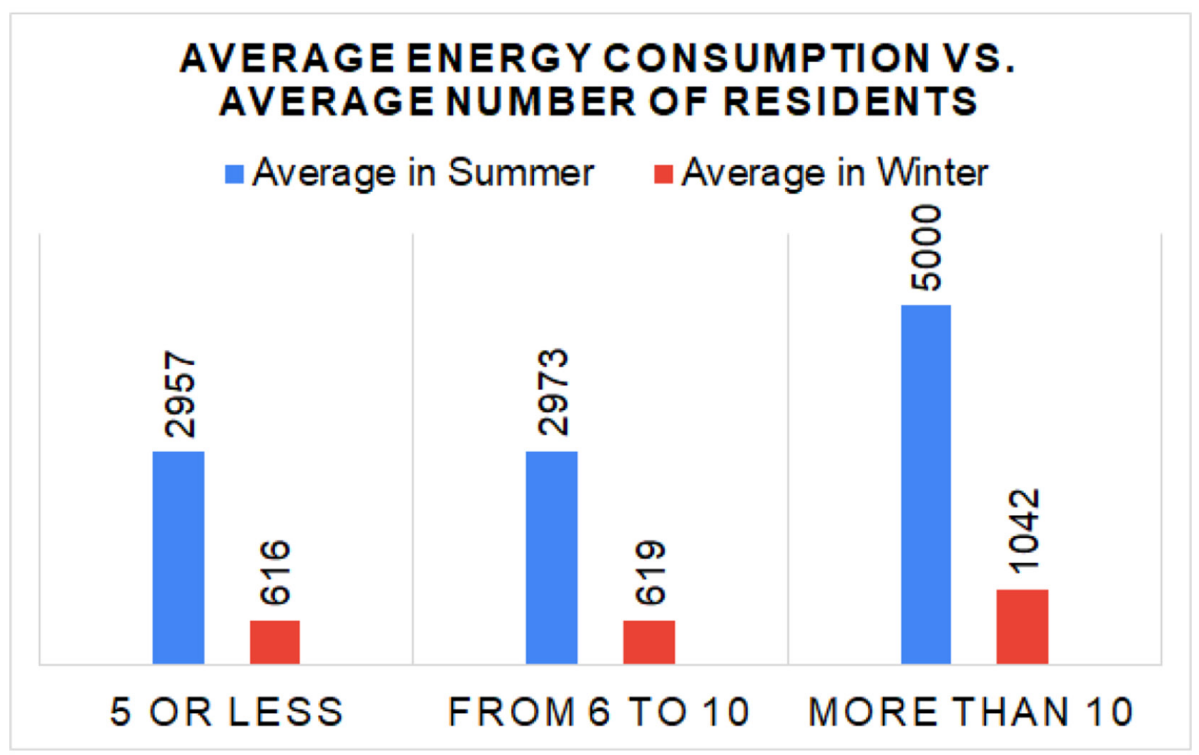

(b)

Figure 9: (a) Ratio of average number of residents; (b) average electricity consumption versus average number of residents. 


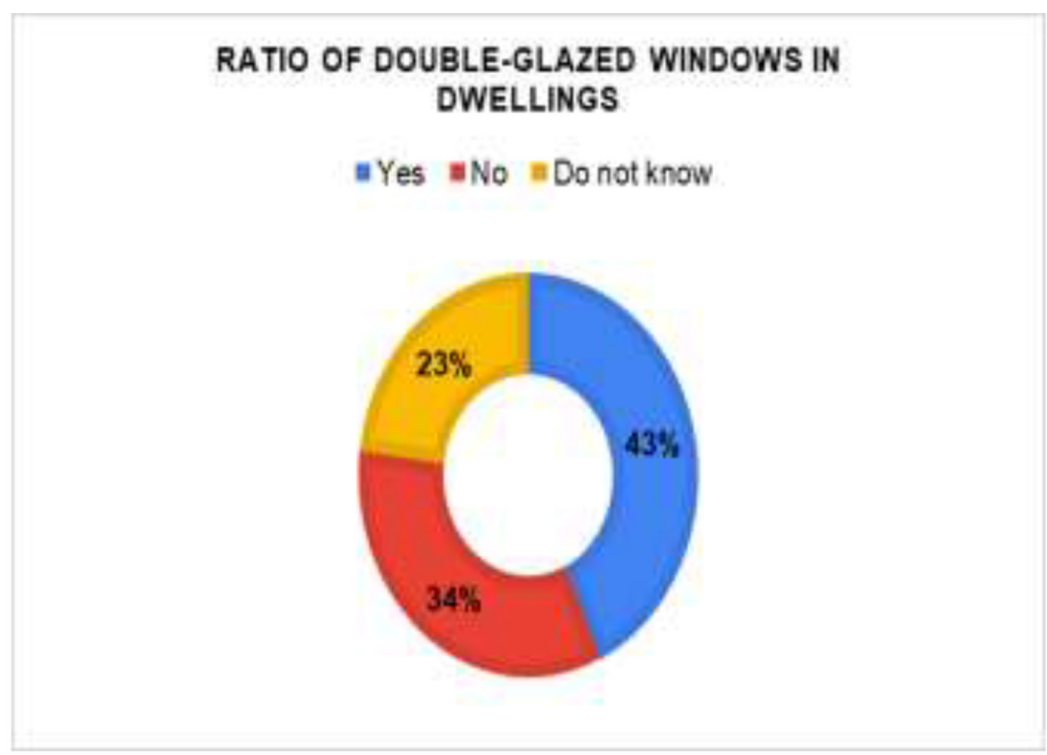

(a)

\section{AVERAGE ENERGY CONSUMPTION IN DWELLINGS WITH DOUBLE. GLAZED WINDOWS DURING SUMMER AND WINTER}

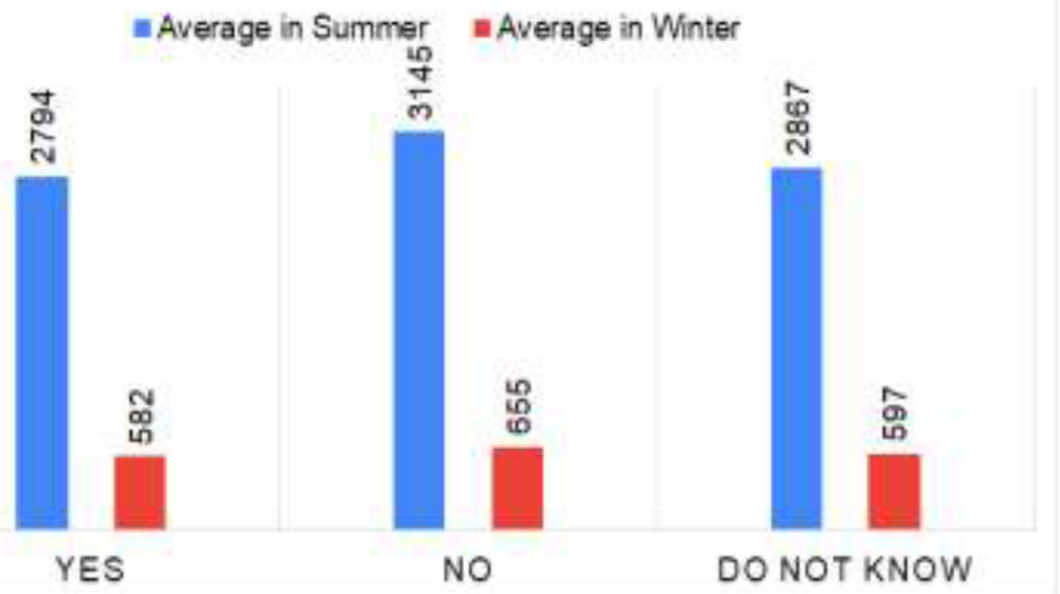

(b)

Figure 10: (a) Ratio of window glazing systems in dwellings; (b) average electricity consumption with/without thermal insulation. 


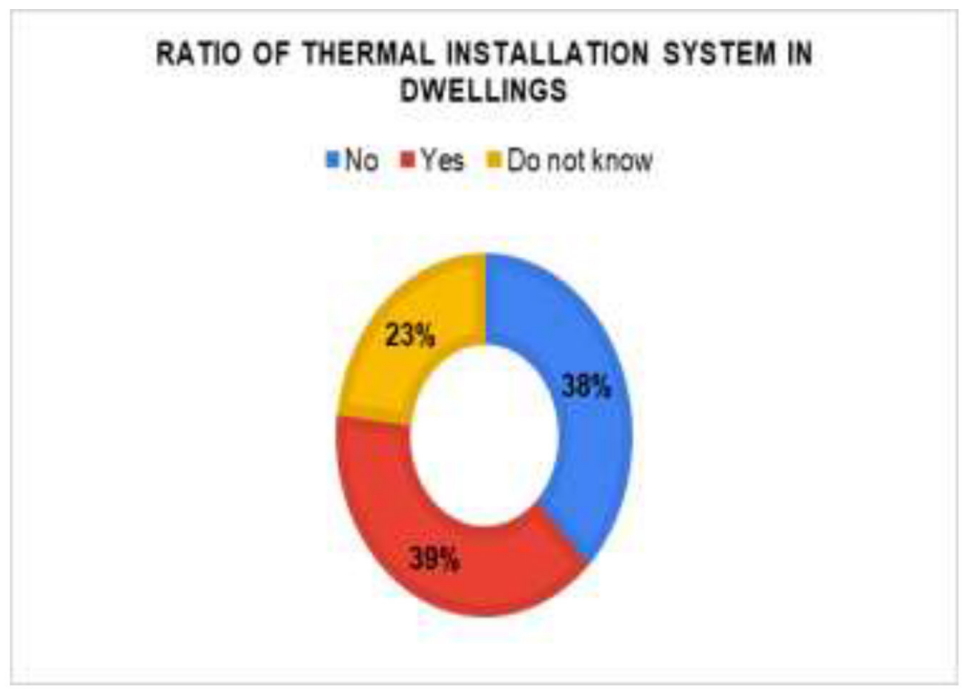

(a)

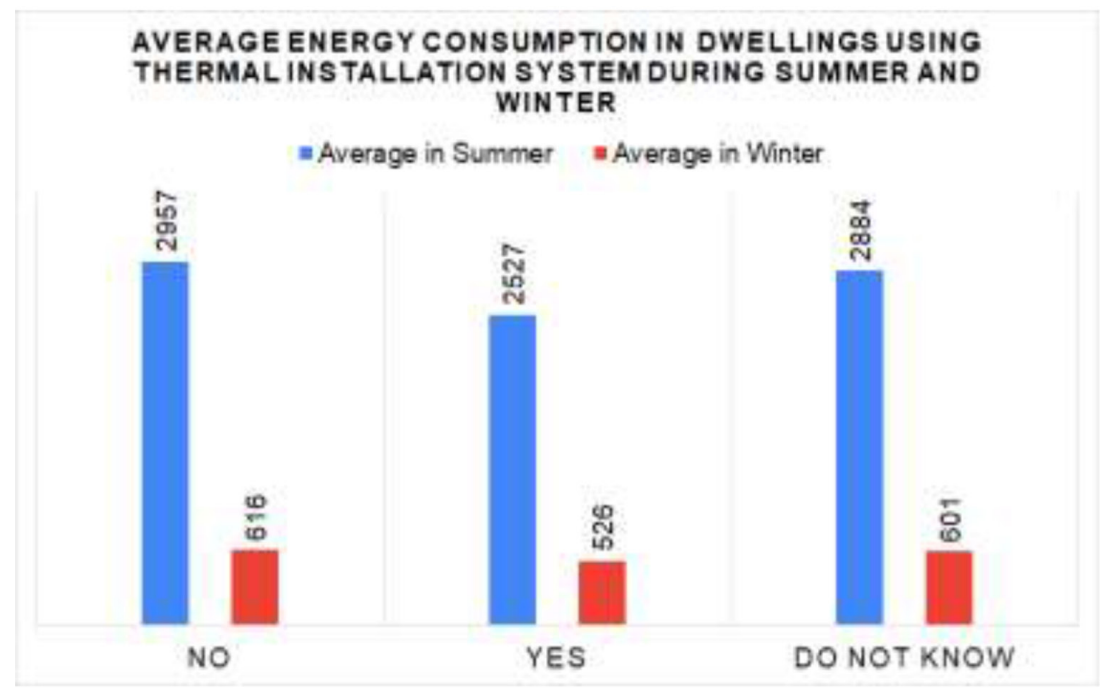

(b)

Figure 11: (a) Ratio of thermal installation system; (b) average electricity consumption with/ without thermal insulation system.

\section{REFERENCES}

[1] Al Haqwi, A., Al Drees, T., Al Rumayyan, A., Al Farhan, A., Alotaibi, S., Al Khashan, H. \& Badri, M., Shared clinical decision making. A Saudi Arabian perspective. Saudi Medical Journal, 36(12), pp. 1472-1476, 2015. https://doi.org/10.15537/ smj.2015.12.13682

[2] Alaidroos, A. \& Krarti, M., Optimal Design of residential building envelope systems in the Kingdom of Saudi Arabia. Energy and Buildings, 86, pp. 104-117, 2015. https:// doi.org/10.1016/j.enbuild.2014.09.083 
[3] Felimban, A., Prieto, A., Knaack, U., Klein, T. \& Qaffas, Y., Assessment of current energy consumption in residential buildings in Jeddah. Saudi Arabia. Buildings, 9(7), pp. 1472-1476, 2019.

[4] Alrashed, F. \& Asif, M., Trends in residential energy consumption in Saudi Arabia with particular reference to the eastern province. Journal of Sustainable Development of Energy, Water and Environment Systems, 2, pp. 376-387, 2014. https://doi. org/10.13044/j.sdewes.2014.02.0030

[5] Aldossary, N., Rezgui, Y. \& Kwan, A., Establishing domestic low energy consumption reference levels for Saudi Arabia and the Wider Middle Eastern Region. Sustainable Cities and Society, 28, pp. 265-276, 2017. https://doi.org/10.1016/j.scs.2016.09.015

[6] Holopainen, R., Salmi, K., Kähkönen, E., Pasanen, P. \& Reijula, K., Primary energy performance and perceived indoor environment quality in Finnish low-electricity and conventional houses. Building and Environment, 87, pp. 92-101, 2015. https://doi. org/10.1016/j.buildenv.2015.01.024

[7] Alyousef, Y. \& Abu-Eid, M., Energy efficiency initiatives for Saudi Arabia on Supply and demand Sides, energy efficiency - A bridge to low Carbon economy. Morvaj, Ed. InTech, pp. 279-308, 2012.

[8] Esmaeil, K., Alshitawi, M. \& Almasri, R., Analysis of energy consumption pattern in Saudi Arabia's residential buildings with specific reference to Qassim region. Energy Efficiency, 12, pp. 2123-2145, 2019. https://doi.org/10.1007/s12053-019-09806-X

[9] Krarti, M., Aldubyan, M. \& Williams, E., Residential building stock model for evaluating energy retrofit programs in Saudi Arabia. Energy, 195, p. 116980, 2020. https://doi. org/10.1016/j.energy.2020.116980

[10]Albogami, M. \& Boukhanouf, R., Residential building energy performance evaluation for different climate zones. Earth and Environmental Science, 329, p. 012026, 2019. https://doi.org/10.1088/1755-1315/329/1/012026

[11] Monthly Weather Forecast and Climate, Dhahran, Saudi Arabia, www.jeddah.gov.sa/ English/JeddahCity/About/index.php. Accessed on: 7 November 2020.

[12] Monthly Weather Forecast and Climate, Dhahran, Saudi Arabia, www.weather-atlas. com/en/saudi-arabia/dhahran-climate. Accessed on: 1 November 2020.

[13] Indraganti, M. \& Boussaa, D., A method to estimate the heating and cooling degree-days for different climatic zones of Saudi Arabia. Building Services Engineering Research and Technology, 38, pp. 1-24, 2016. https://doi.org/10.1177/0143624416681383

[14] Yan, M., Aun Chan, C., Gygax, A., Yan, J., Campbell, L., Nirmalathas, A. \& Leckie, C., Modelling the total energy consumption of mobile network services and applications. Energies, 12(1), p. 184, 2019. https://doi.org/10.3390/en12010184

[15] Saudi Electricity Company, www.se.com.sa/ar-sa/Pages/home.aspx. Accessed on: 1 November 2020.

[16] Jeddah Municipality, www.minitab.com/en-us/products/minitab/free-trial/. Accessed on: 2 November 2020.

[17] Chekired, F., Smara, Z., Mahrane, A., Chikh, M., \& Berkane, S., An energy flow management algorithm for a photovoltaic solar home, 8th International Conference on Sustainability in Energy and Buildings, SEB-16, 11-13 September 2016, Turin, Italy.

[18] Asadinejad, A., Rahimpour, A., Tomsovic, K., Qi, H. \& Chen, C., Evaluation of residential customer elasticity for incentive based demand response programs. Electric Power Systems Research, 158, pp. 26-36, 2018. https://doi.org/10.1016/j.epsr.2017.12.017 